NK

9461

T971

1908

CHMERAD

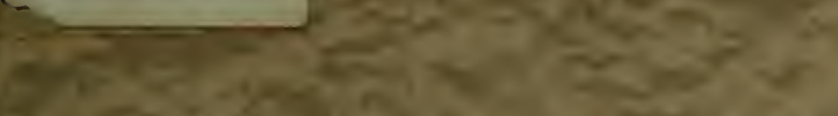

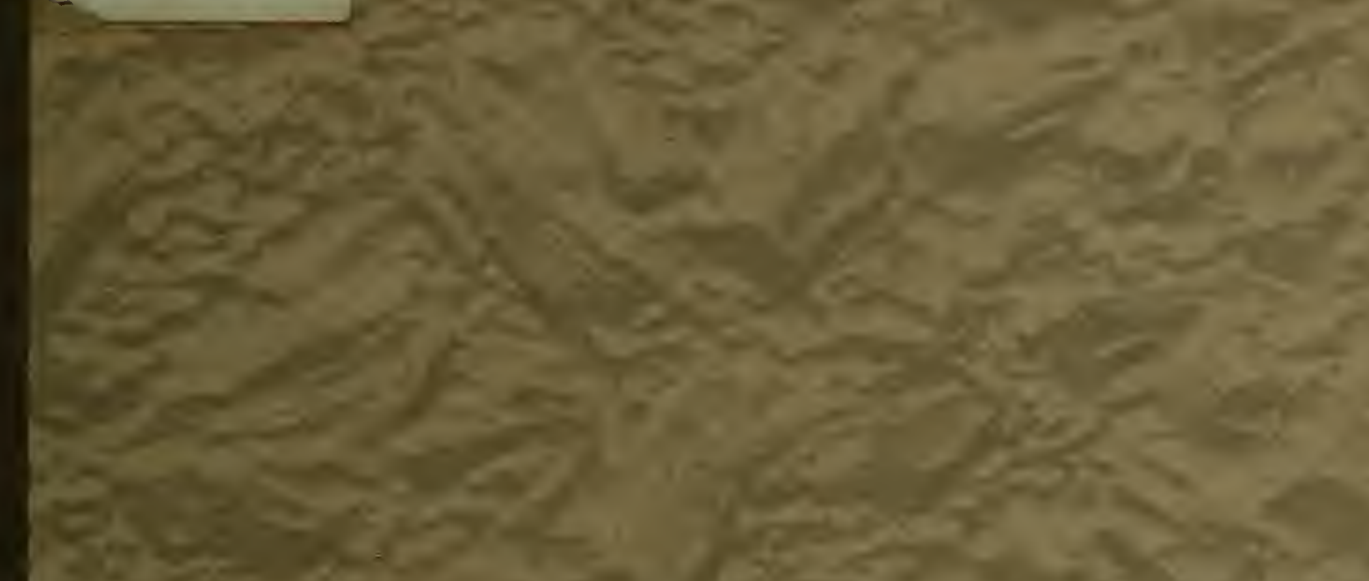

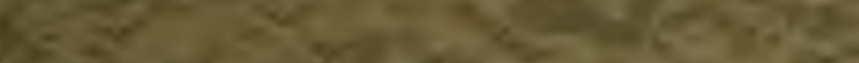

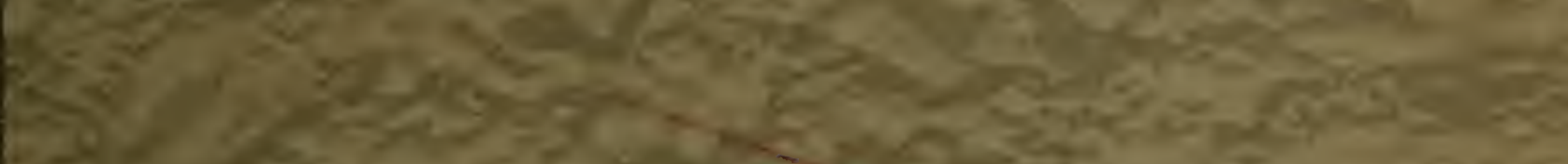

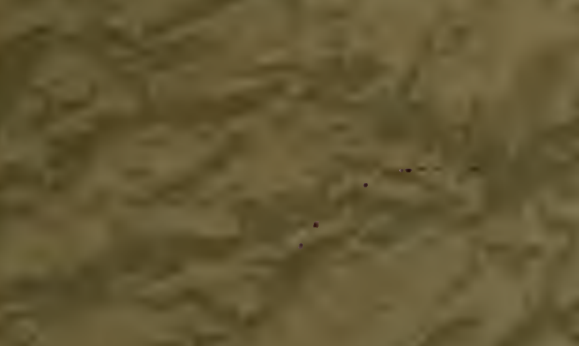

$-4$

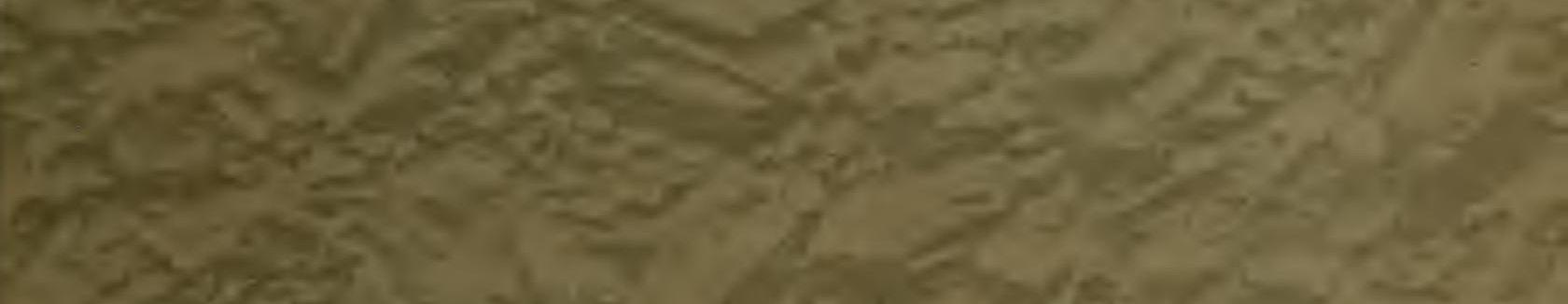

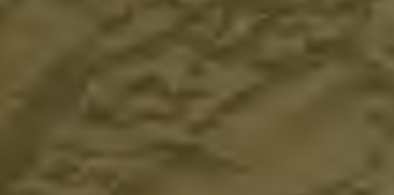

$2+5$ 5

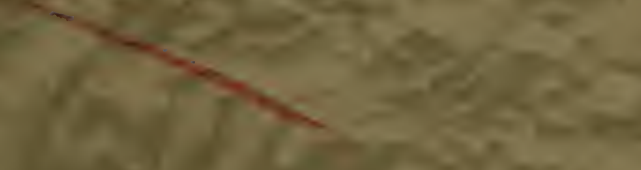

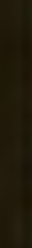

Tis

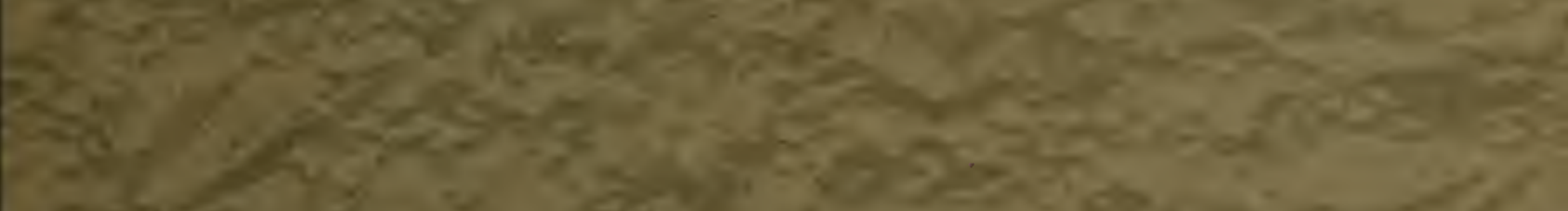
1

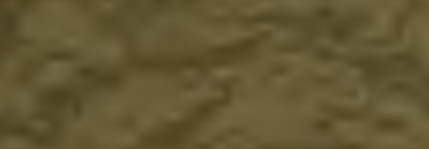

ats 


\section{THE TWENTIETH}

= CENTURY

\section{PATTERN BOOK}

FOR

\section{NORWEGIAN LACE}

$\overline{\overline{\mathrm{AND}}}$ EMBROIDERY

$\overline{\text { ELISE H. SILLJAN }}$

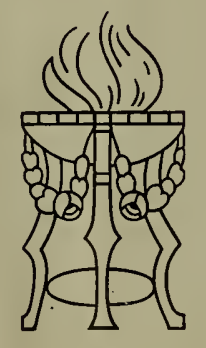

PRINTED BY GRØNDAHL \& SØN

KRISTIANIA :: NORWAY :: 1908 


\section{ALTERKLÆDE}
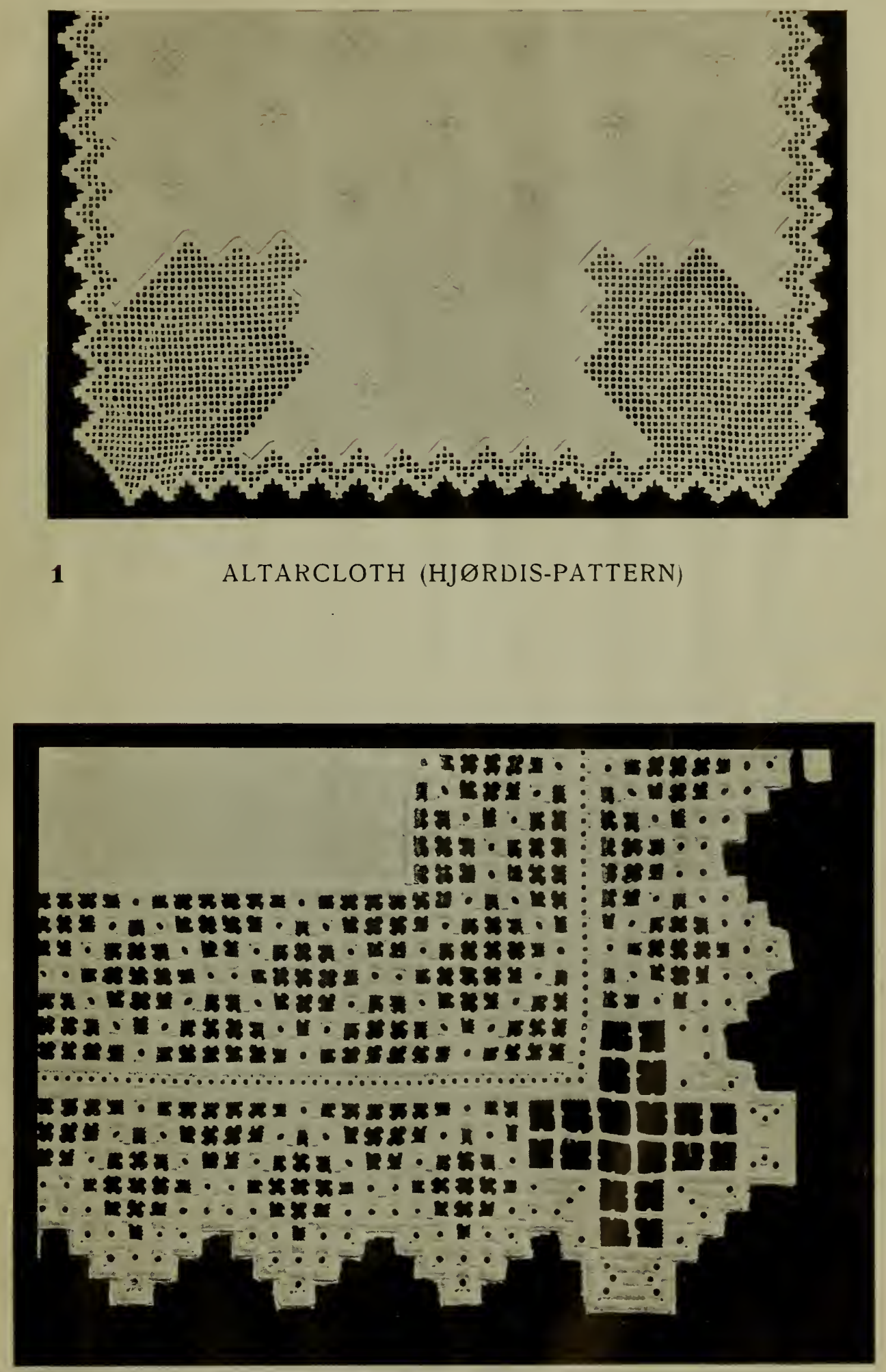


\section{GARDINER}

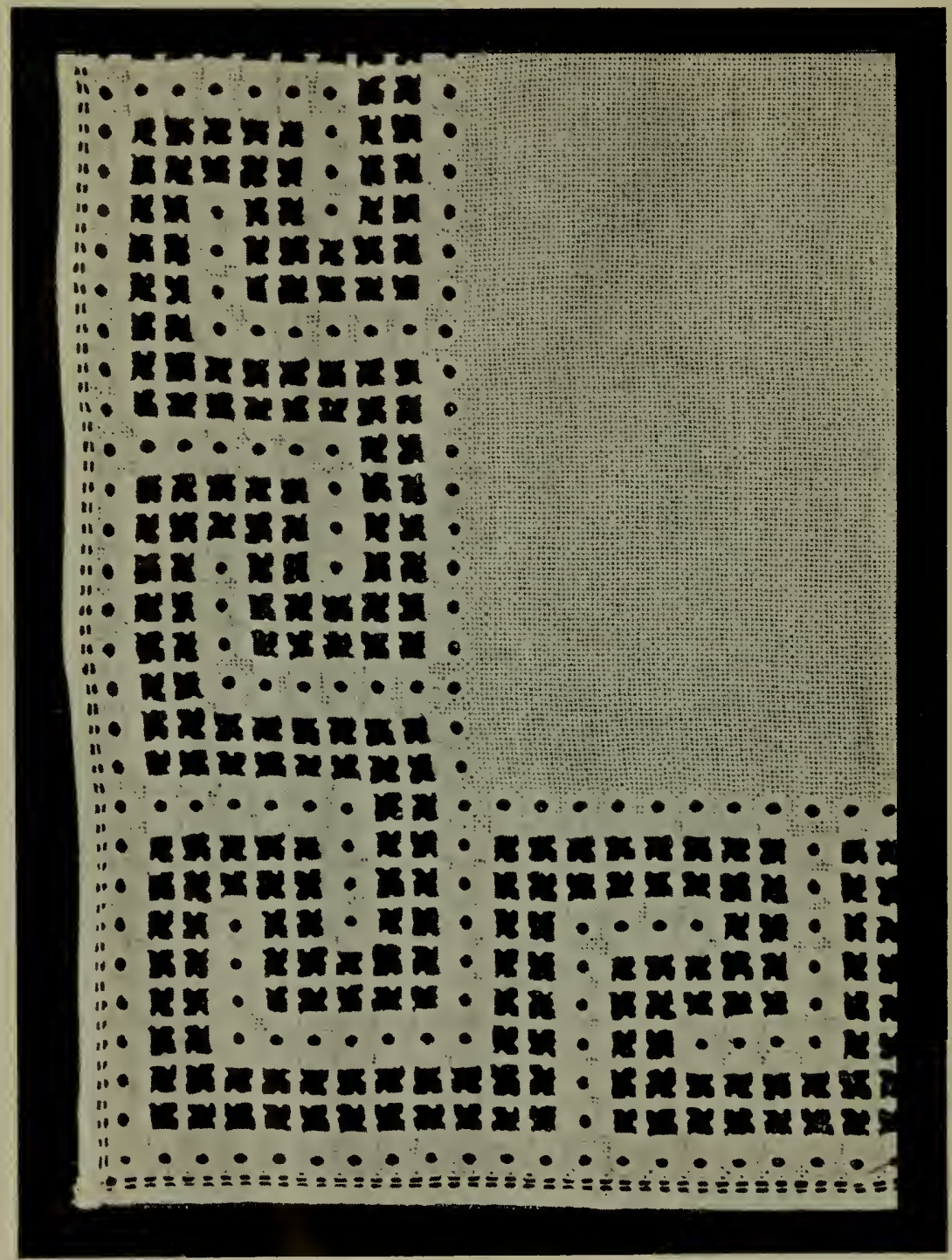




\section{GARD I NER}

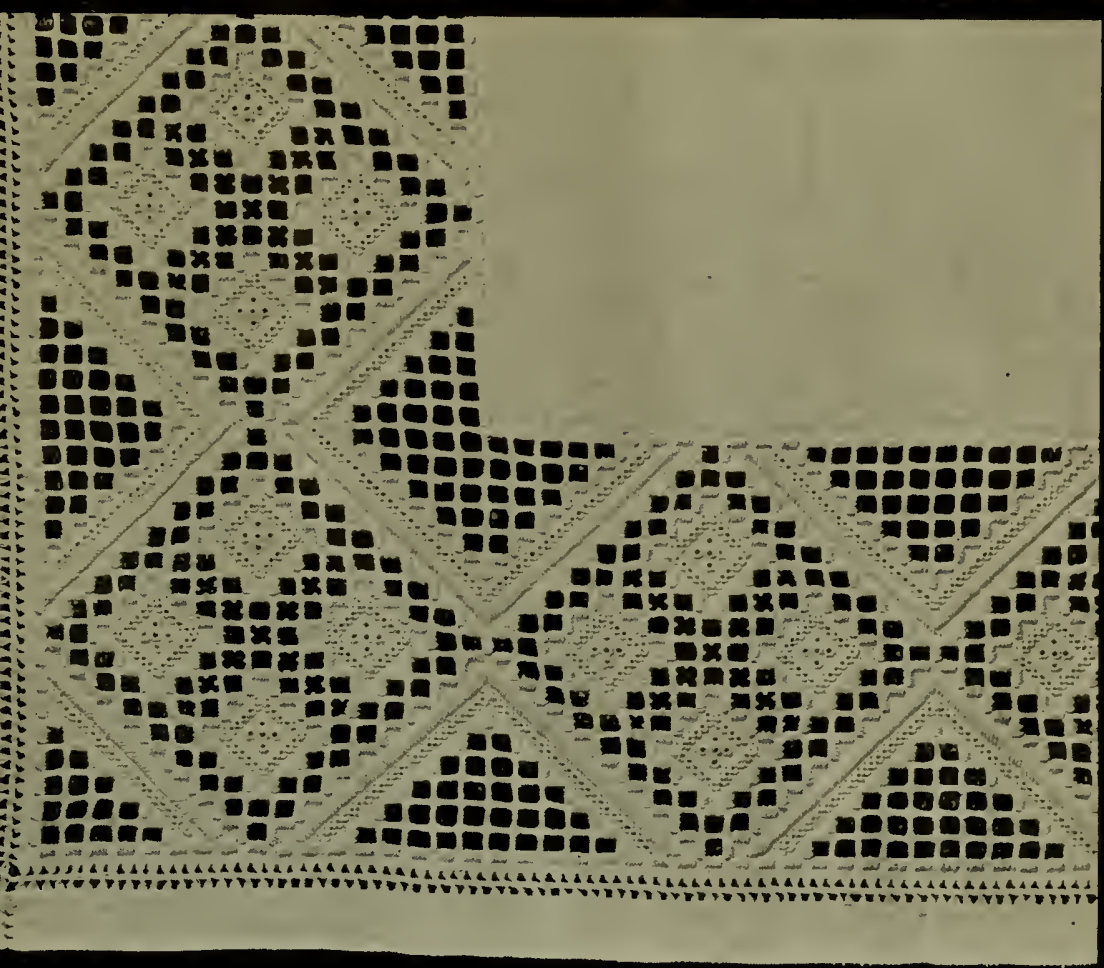

4

CURTAIN

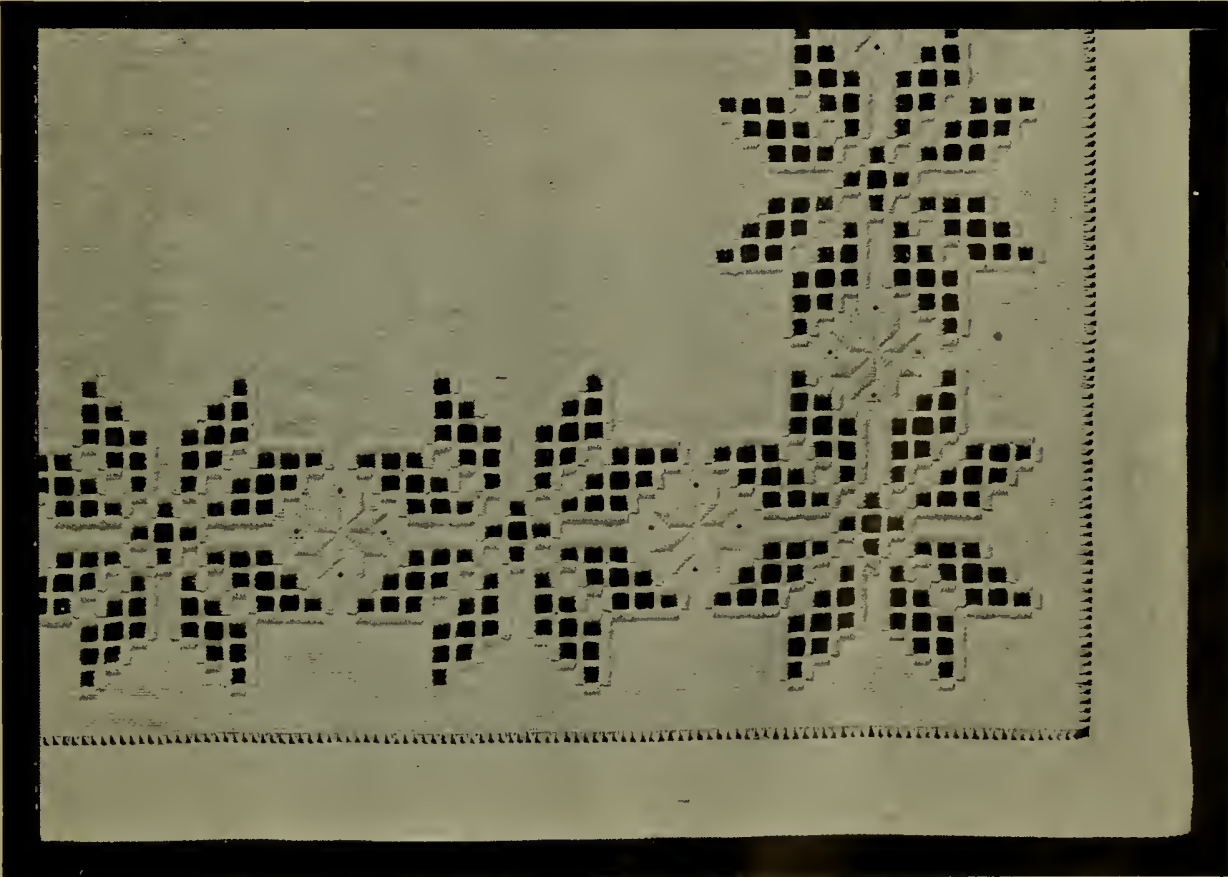

5

CURTAIN 


\section{SERVIETTER}

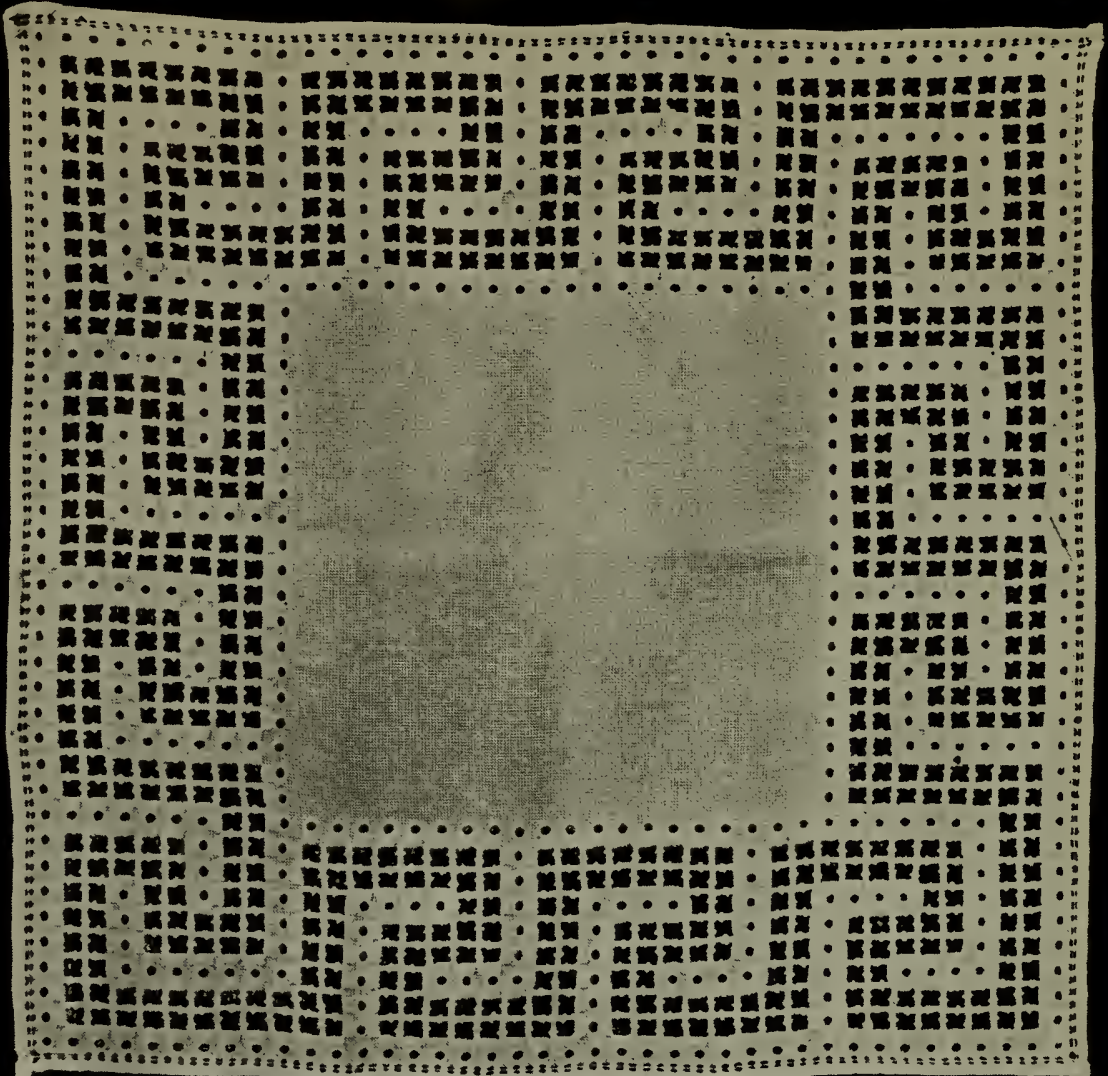

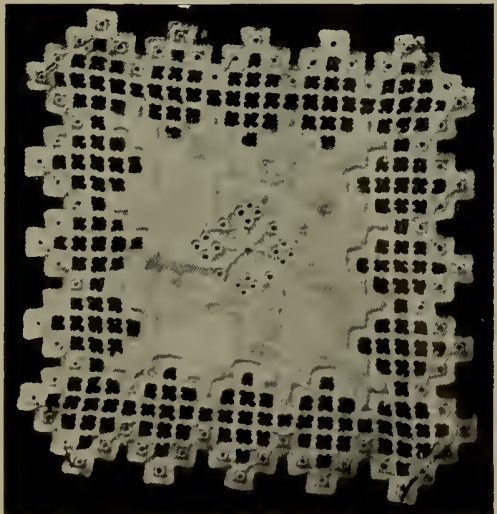

$\mathbf{Z}$

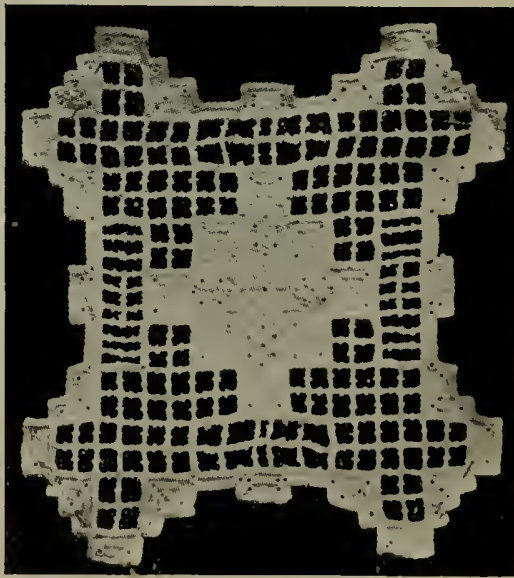

8
DOILY 


\section{SERVIETTER}
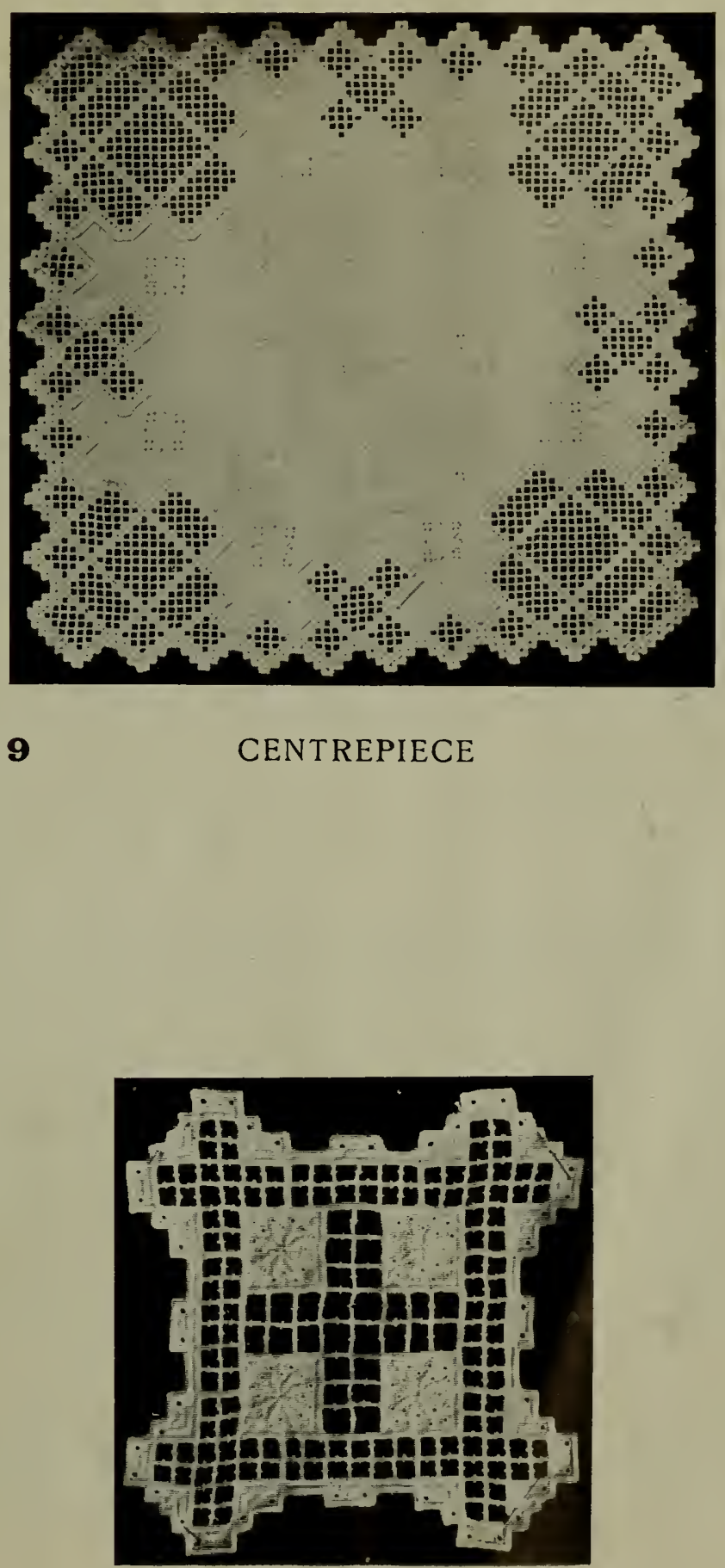

10

DOILY 


\section{KRAVES AET}

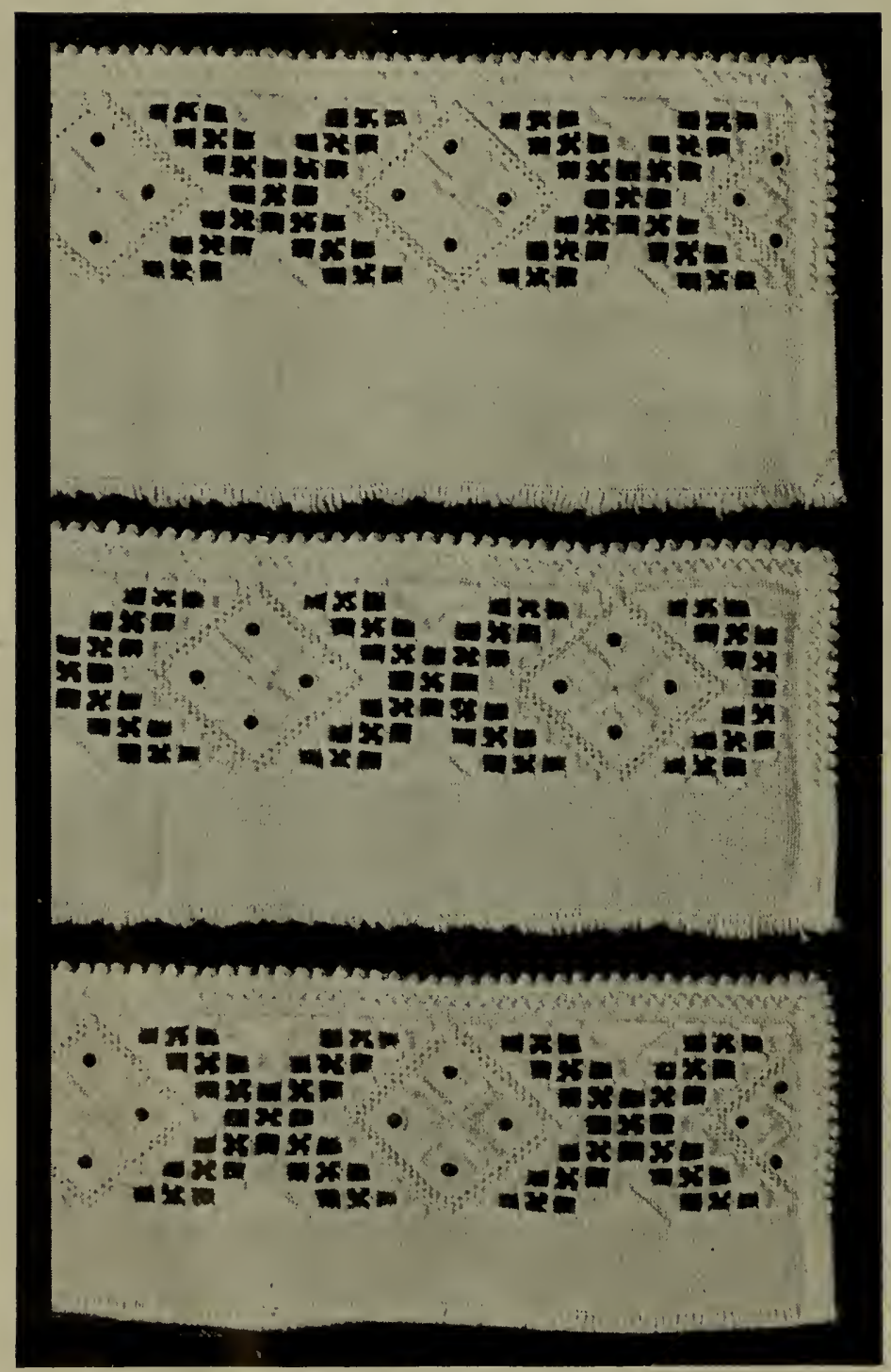




\section{BUFFETDUG}

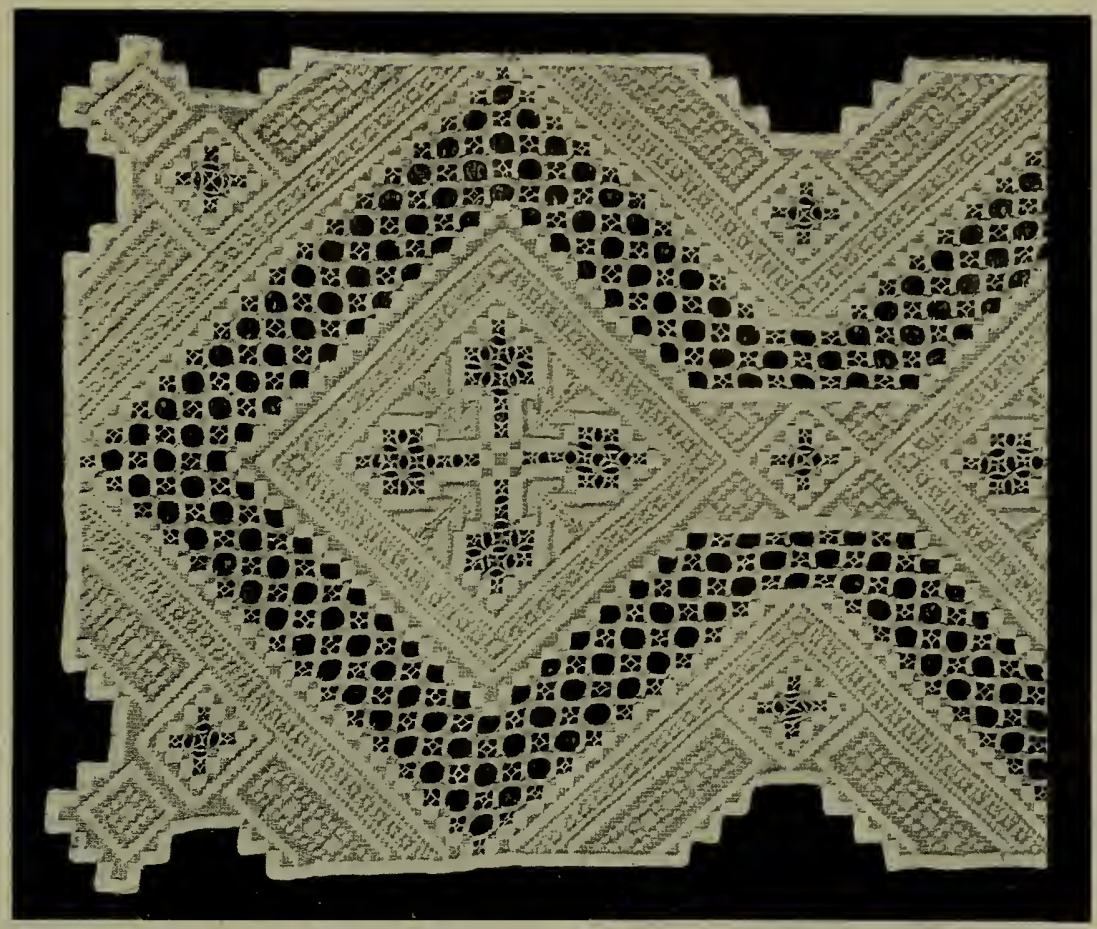

12

SIDEBOARD \& BUREAUCOVER

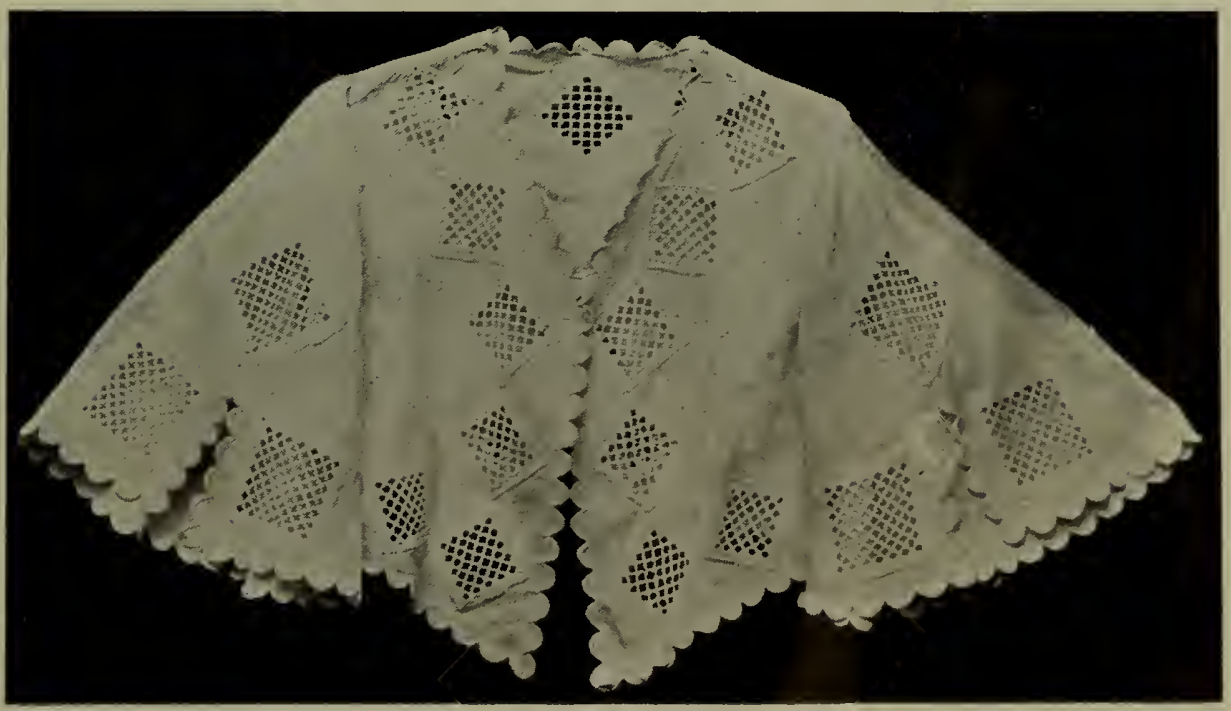

JACKET APPLIQUE WORK 


\section{HAAN D KLAEDEBORDER}

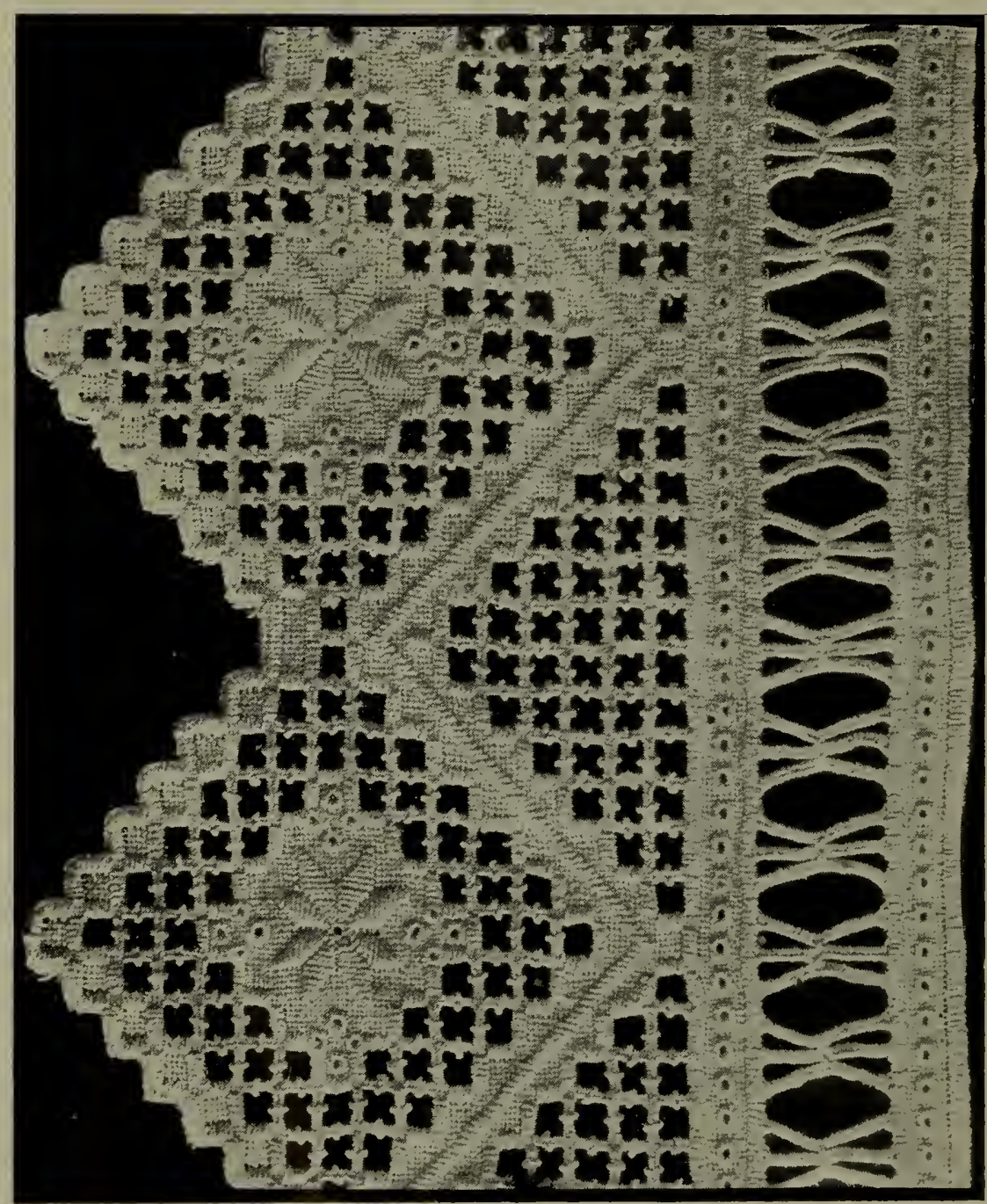

14

BORDER FOR TAWL 


\section{HAANDKLAEDBORDER}

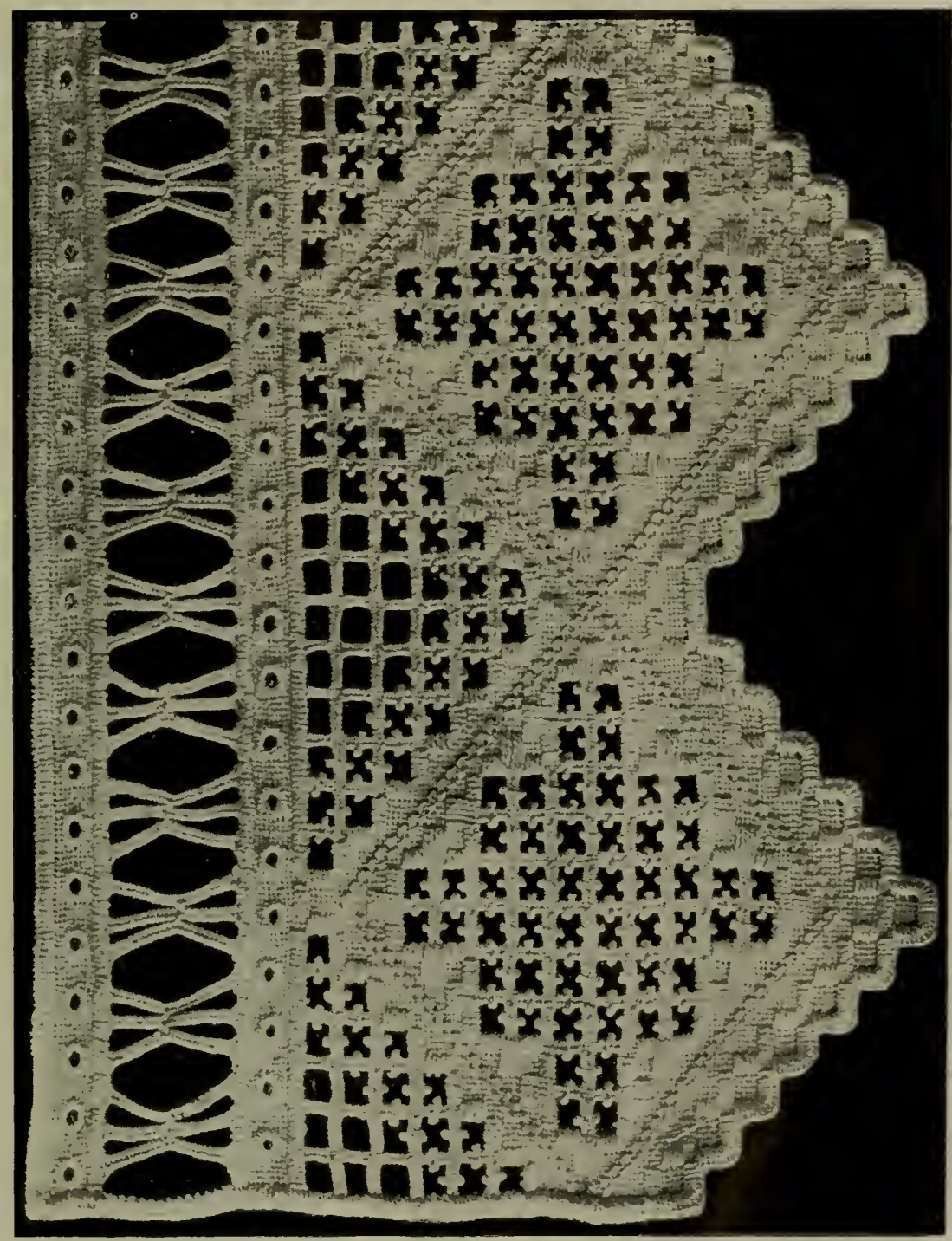




\section{SENGET/EPPE}

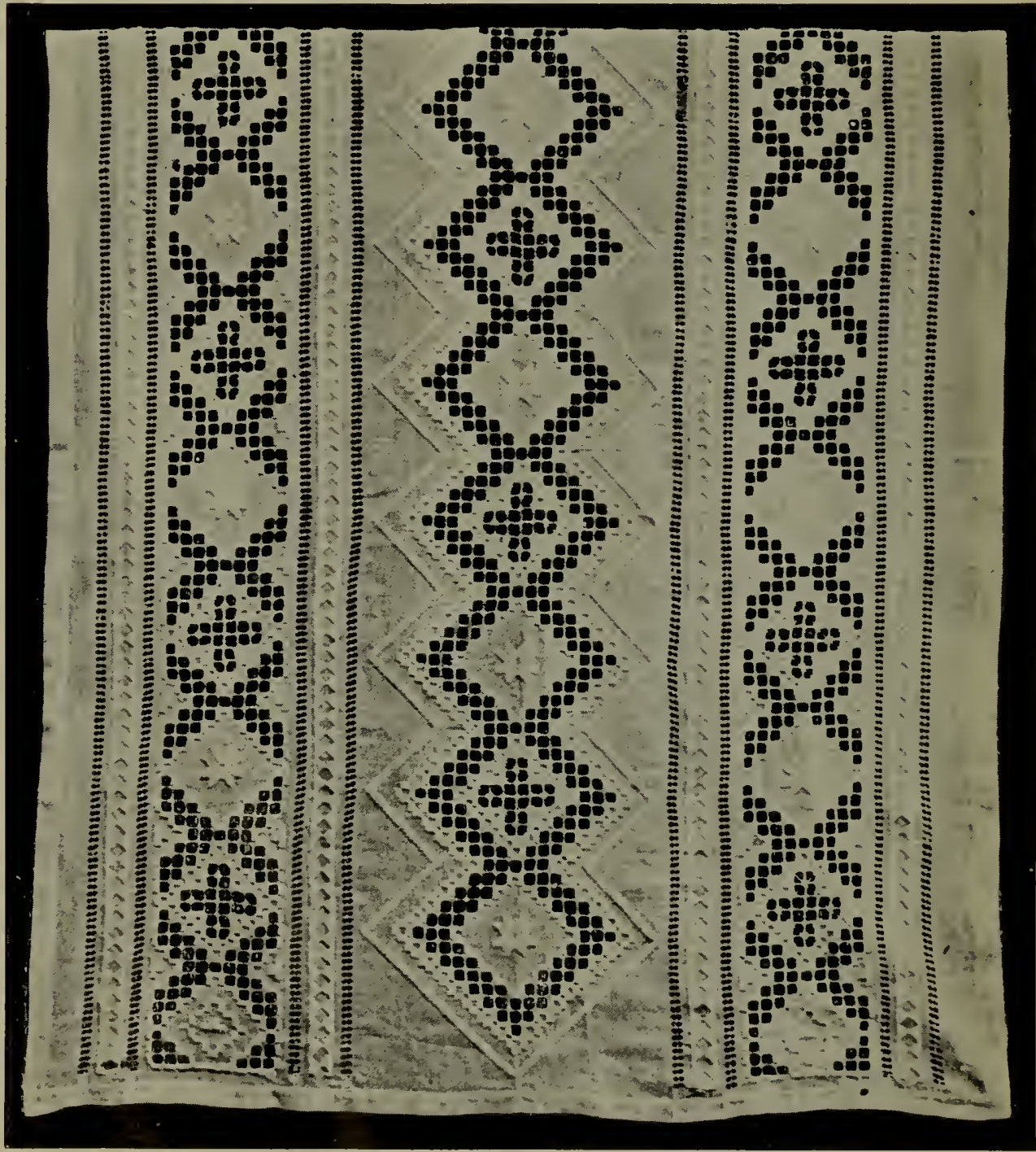

BEDSPREAD 


\section{MELLEMVARK}

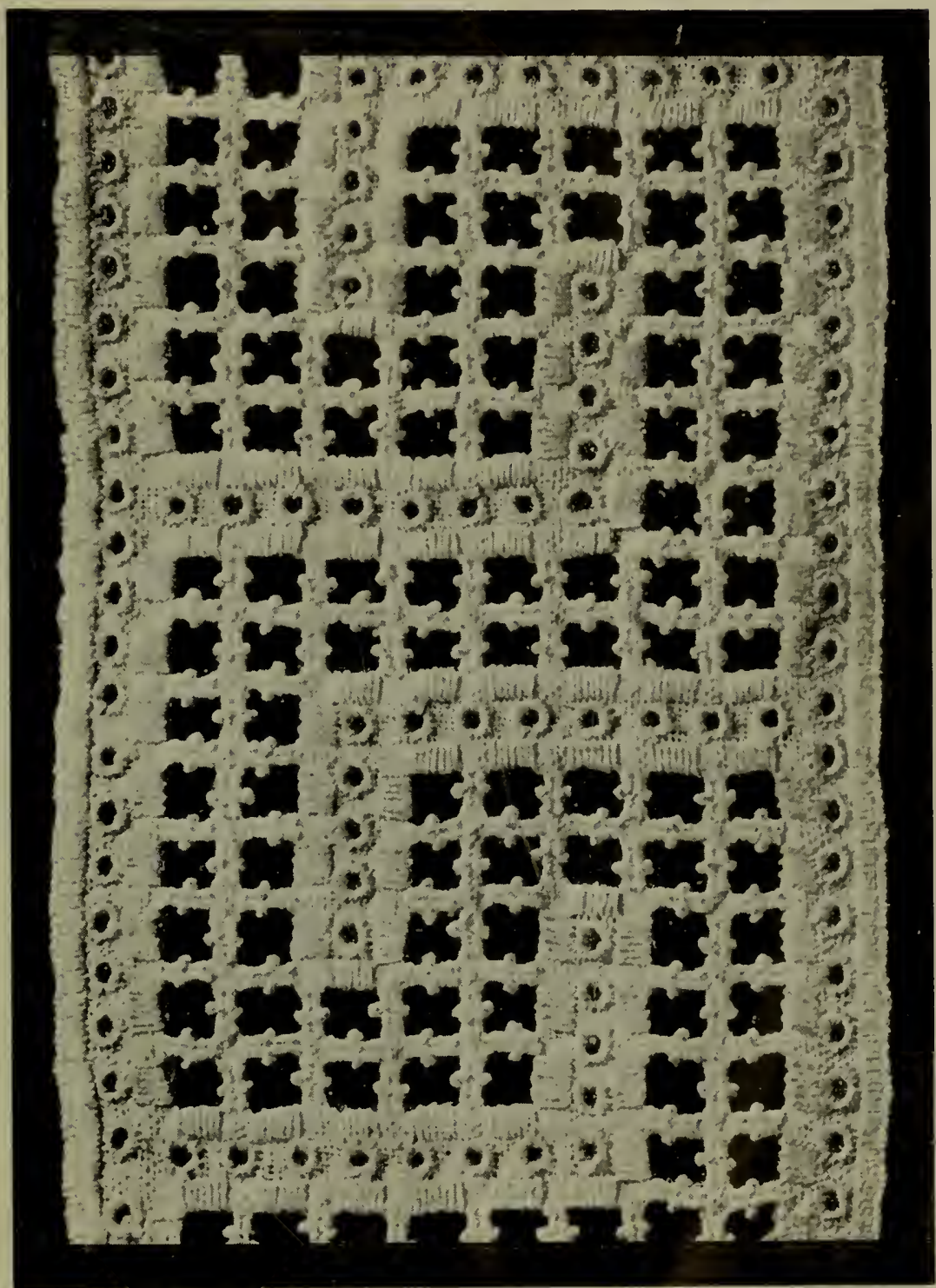

INSERTION 


\section{MELLEMVARK}

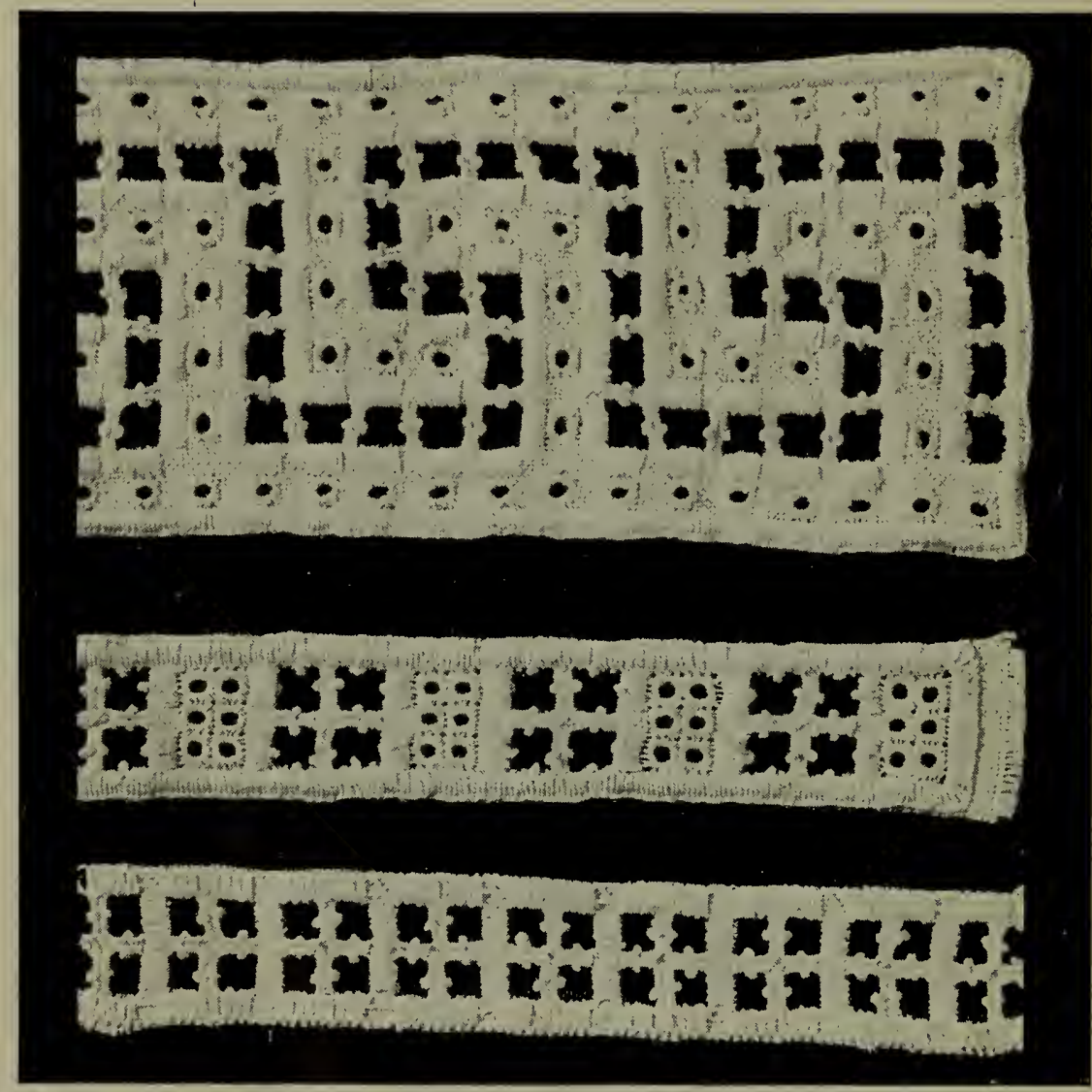


FIRKANTER FOR APPLIQUÉ

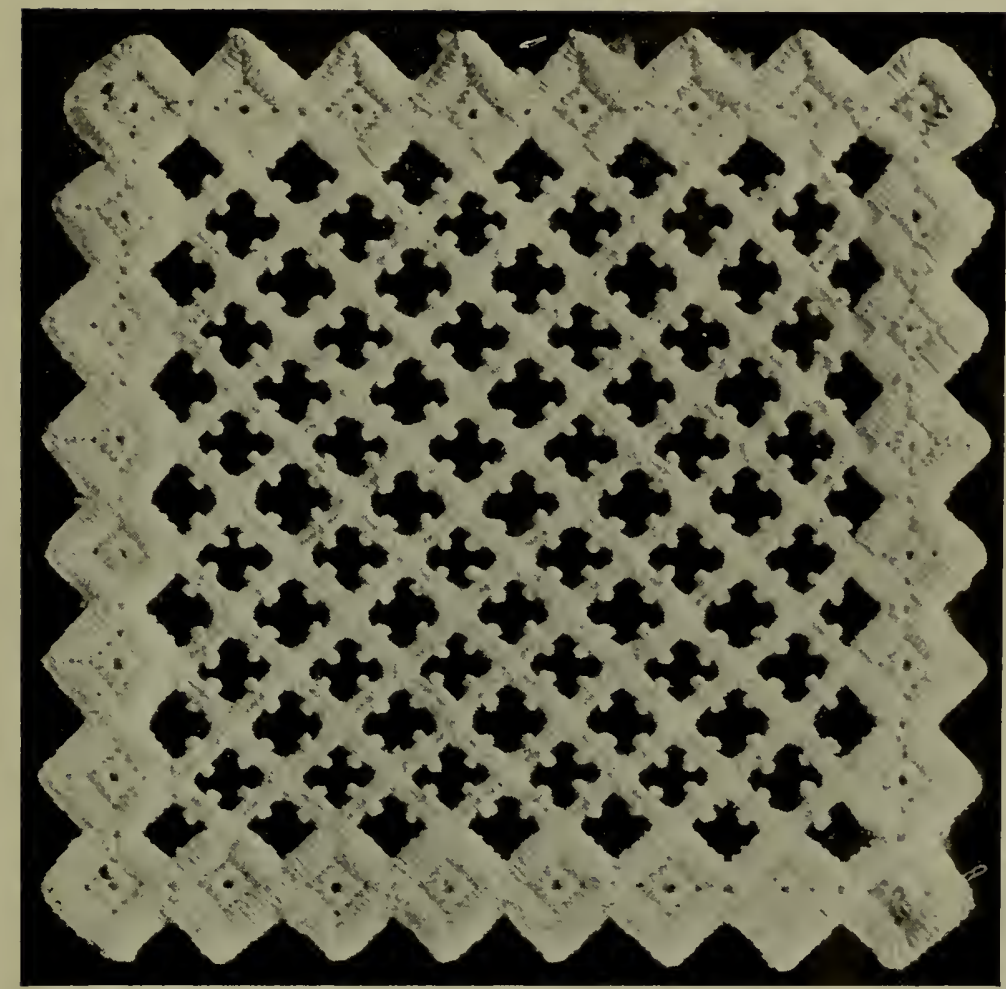




\section{FIRLANTER FOR APPLIQUÉ}

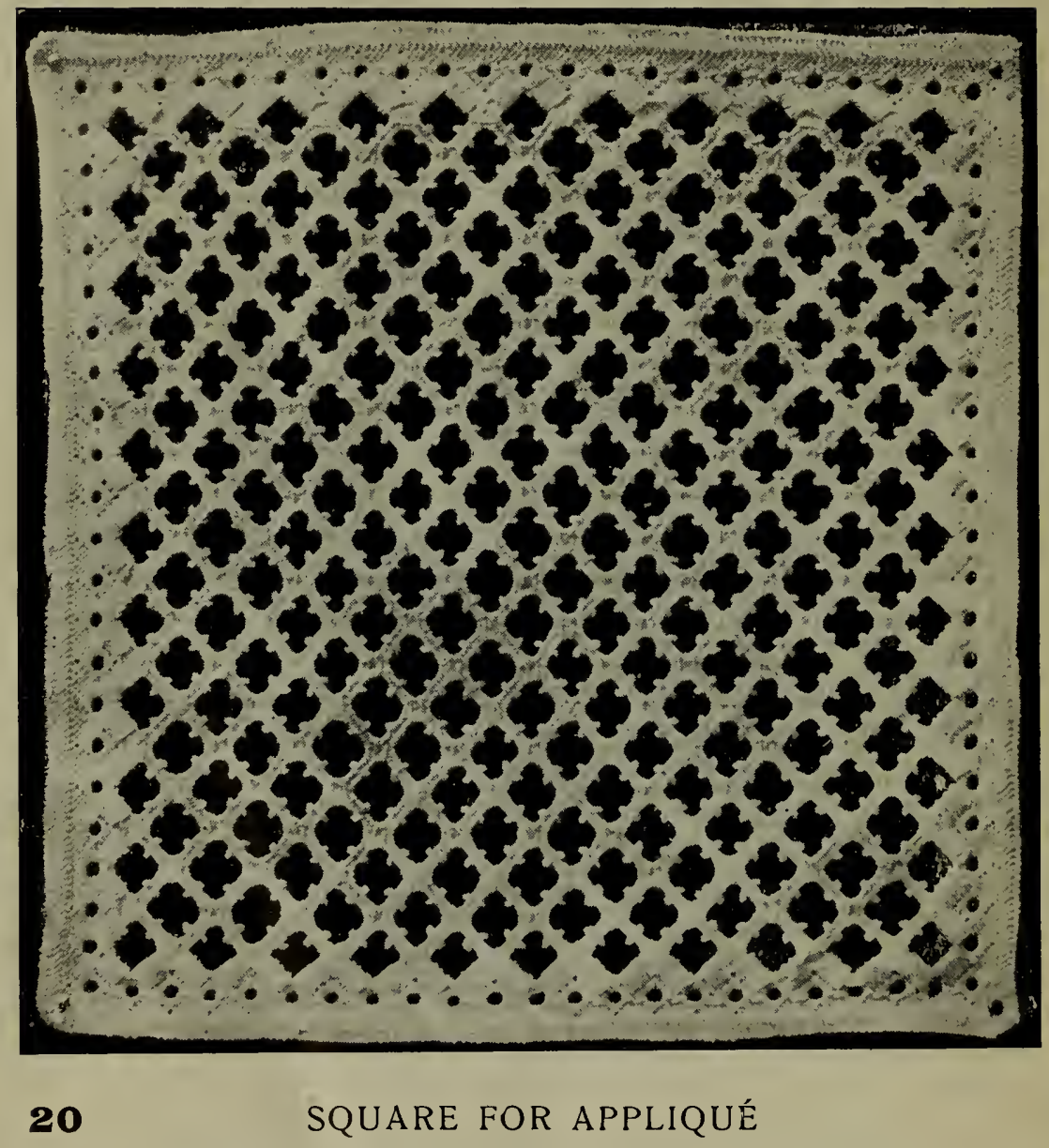




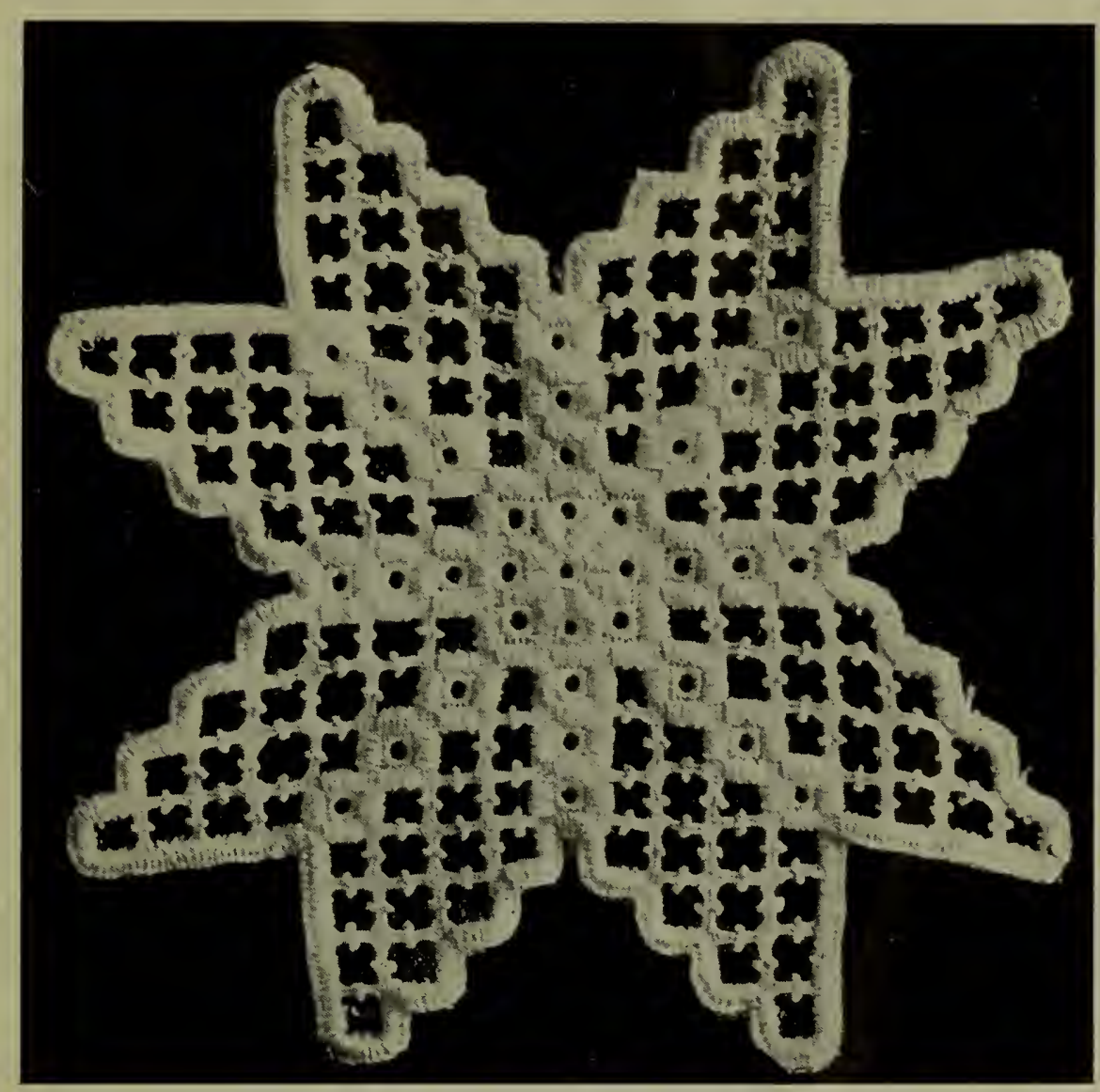

21

STAR APPLIQUÉ 


\section{MELLEMVÆRK OG BLONDER}

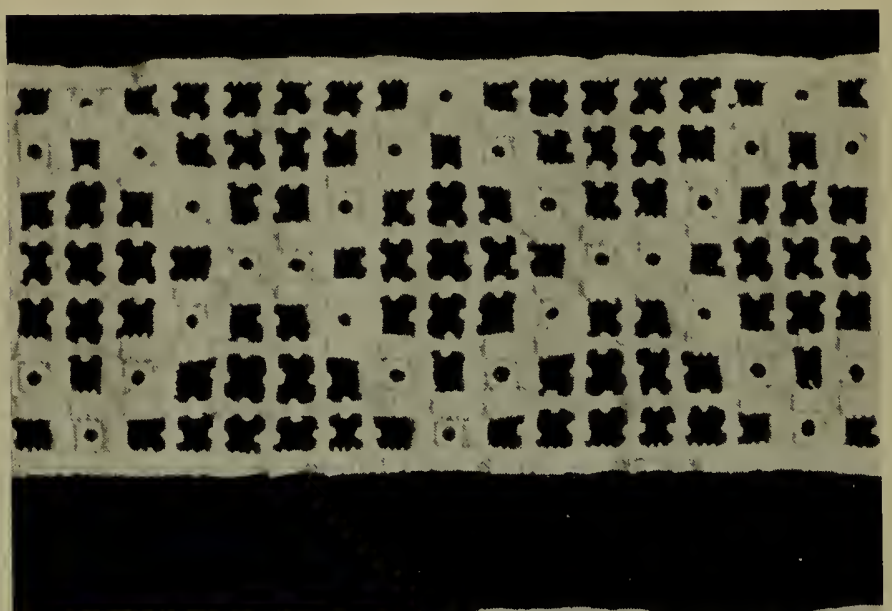

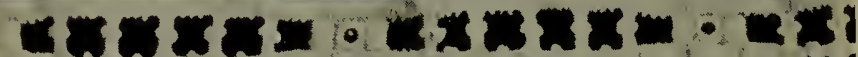

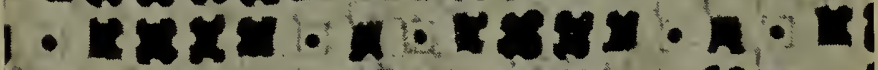

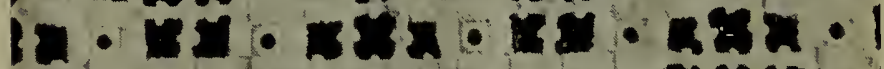
I5.

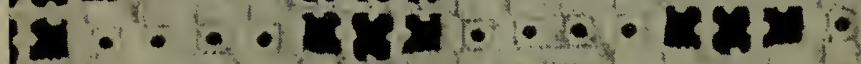

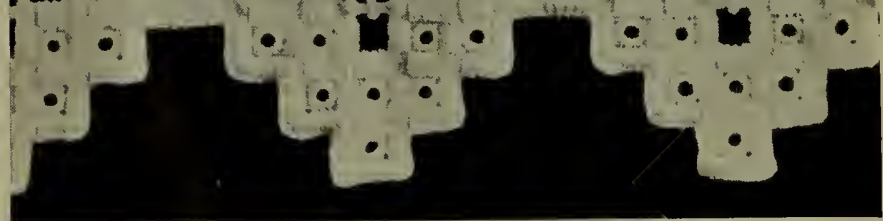


Gaylord

PAMPHLT BINEER
syrcuses, N. r.
Stockton, Calif. 
